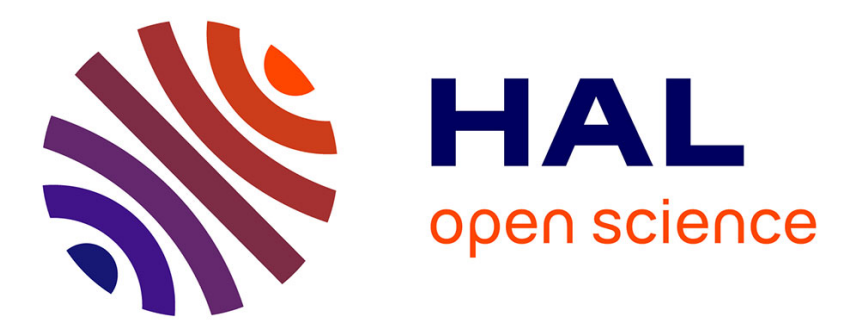

\title{
Non-Monetary Feedback Induces more Cooperation: Students and Workers in a Voluntary Contribution Mechanism
}

Davide Dragone, Fabio Galeotti, Raimondello Orsini

\section{To cite this version:}

Davide Dragone, Fabio Galeotti, Raimondello Orsini. Non-Monetary Feedback Induces more Cooperation: Students and Workers in a Voluntary Contribution Mechanism. 2016. halshs-01282844

\section{HAL Id: halshs-01282844 \\ https://shs.hal.science/halshs-01282844}

Preprint submitted on 4 Mar 2016

HAL is a multi-disciplinary open access archive for the deposit and dissemination of scientific research documents, whether they are published or not. The documents may come from teaching and research institutions in France or abroad, or from public or private research centers.
L'archive ouverte pluridisciplinaire HAL, est destinée au dépôt et à la diffusion de documents scientifiques de niveau recherche, publiés ou non, émanant des établissements d'enseignement et de recherche français ou étrangers, des laboratoires publics ou privés. 


\title{
GATE

UMR 5824

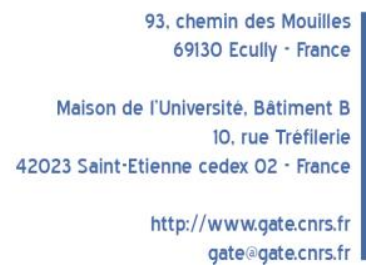

WP 1612 - March 2016

\section{Non-Monetary Feedback Induces more Cooperation: Students and Workers in a Voluntary Contribution Mechanism}

\author{
Davide Dragone, Fabio Galeotti, Raimondello Orsini
}

\begin{abstract}
:
We conduct an artefactual field experiment to study and compare the behavior of workers and students in a linear voluntary contribution mechanism in which subjects can assign immaterial sanctions or rewards to the other group members. We find that both students and workers sanction group members who contribute less than the group average, and reward those who contribute more. In both subject samples, the use of non-monetary sanctions and rewards induces more cooperation. The magnitude of the effect, however, is heterogeneous, as feedback has more impact among students who, contrary to workers, respond positively to sanctions. Students also tend to use sanctions more than workers. We discuss the implications of these findings for social cohesion, cooperative spirit and organizational efficiency in the workplace.
\end{abstract}

Keywords:

public good, field experiment, non-monetary sanctions and rewards, communication, external validity

JEL codes:

C92, C93, H41

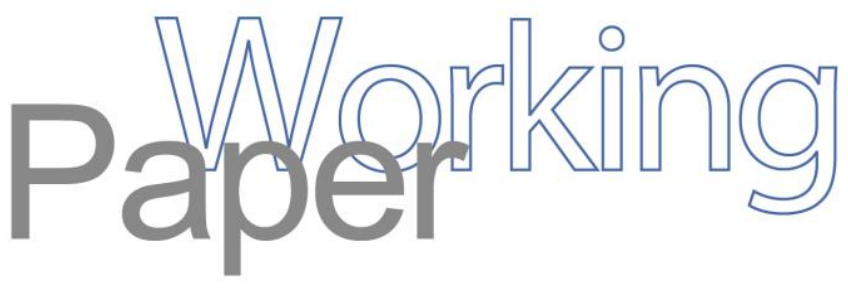




\title{
Non-Monetary Feedback Induces more Cooperation: Students and Workers in a Voluntary Contribution Mechanism
}

\author{
Davide Dragone* ${ }^{*}$ Fabio Galeotti ${ }^{\S}$, and Raimondello Orsini ${ }^{\dagger}$
}

\begin{abstract}
We conduct an artefactual field experiment to study and compare the behavior of workers and students in a linear voluntary contribution mechanism in which subjects can assign immaterial sanctions or rewards to the other group members. We find that both students and workers sanction group members who contribute less than the group average, and reward those who contribute more. In both subject samples, the use of non-monetary sanctions and rewards induces more cooperation. The magnitude of the effect, however, is heterogeneous, as feedback has more impact among students who, contrary to workers, respond positively to sanctions. Students also tend to use sanctions more than workers. We discuss the implications of these findings for social cohesion, cooperative spirit and organizational efficiency in the workplace.
\end{abstract}

Keywords: public good, field experiment, non-monetary sanctions and rewards, communication, external validity.

JEL codes: C92, C93, H41

\section{Introduction}

A social norm prescribes or forbids a given behavior, and its enforcement can be sustained by a system of incentives that reward desirable behavior and sanction deviant behavior (see, e.g., Bicchieri, 2005). Social norms such as fairness, cooperation, and reciprocity may play an important role in mitigating opportunistic behavior and fostering cooperation in social dilemmas. A large body of research has mainly focused on the Voluntary Contribution Mechanism (VCM), and measured the effect of monetary sanctions (e.g. Fehr and Gächter, 2000) and rewards (e.g. Sefton et al., 2007) on cooperation. As observed by several scholars, however, individuals do not only care about their monetary payoffs, but also about other non-monetary factors. When this is the case, informal and non-material sanctions and rewards can be effective in encouraging group-oriented behavior (see, e.g., Masclet et al., 2003, Dugar, 2013, Bradler et al., 2013; Peeters and Vorsatz, 2013, Zylbersztejn, 2015).

Understanding the effect of non-monetary sanctions and rewards can be useful to design communication mechanisms which reduce opportunistic behavior and increase organizational efficiency. Depending on the environment, negative non-monetary feedback (e.g. social disapproval, peer pressure, ostracism) and positive non-monetary feedback (e.g. social acceptance,

\footnotetext{
* University of Bologna, Department of Economics, Piazza Scaravilli 2, 40126 Bologna, Italy; E-mail: davide.dragone@unibo.it.

$\S$ Corresponding author. Université de Lyon, Lyon, 69007, France; CNRS, GATE Lyon Saint-Etienne, Ecully, 69130, France. E-mail: galeotti@gate.cnrs.fr. Phone: +33 (0) 4728660 38; address: GATE Lyon St. Etienne, 93 Chemin des Mouilles, 69130 Ecully, France.

$\uparrow$ University of Bologna, Department of Economics, Strada Maggiore 45, 40125 Bologna, Italy; E-mail: raimondello.orsini@unibo.it.
} 
approval and recognition) may be simpler to implement and cheaper than other sanction/reward systems based on monetary sanctions, monitoring and vertical control.

Typically, the existing experimental literature studies the effectiveness of monetary and nonmonetary sanctions employing undergraduate students as experimental subjects. ${ }^{1}$ This opens the issues of the external validity of the reported experimental results, and the robustness of the findings when using different experimental pools, such as workers or older age people (Harrison and List, 2004). In this paper we address this issue by investigating whether the existing experimental results on the effectiveness of informal sanctions and rewards are robust when considering a sample of workers. To this aim, we conduct an artefactual field experiment to compare the propensity to cooperate and the sensitivity to non-monetary feedback (sanctions and rewards in the form of emoticons) $)^{2}$ of undergraduate students and workers. ${ }^{3}$

We find that both students and workers assign immaterial sanctions to group members who contribute less than the average contribution, and assign rewards to those that contribute more than the average. Overall, non-monetary feedback induces more cooperation in both students and workers, with heterogeneous results. Students contribute less than workers when feedback is not available, but they catch-up and reach similar cooperation rates with respect to workers when sanctioning or rewarding the others' choices is possible. Workers contribute more when feedback is available but tend to decrease their contribution when disapproved.

The remaining of this paper is organized as follows. Section 2 describes the experimental design. Section 3 presents the results. In Section 4 we discuss our main findings and conclude.

\section{Experimental Design}

We conducted 18 sessions at the University of Bologna (Italy) between July 2009 and January 2011. Each session is composed by students only, or workers only. In total, 96 students and 156 workers participated in the experiment (12 or 24 subjects per session). Students were recruited from the subject pool maintained through ORSEE (Greiner, 2015). Workers were recruited from two different sources: Obiettivo Lavoro (OL), a large Italian recruitment agency (72 workers), and Formula Servizi (FS), a workers co-operative company which operates in Italy ( 84 workers). ${ }^{4}$ All

\footnotetext{
${ }^{1}$ Quoting Dugar (2013, p. 1375), "it is difficult, if not impossible, to capture the effects of non-monetary devices on free-riding behavior by using data from the naturally occurring settings (i.e., organizations) because of the potential endogeneity problem. Organizations that think that non-monetary instruments would work in their setting would selfselect themselves into their use, which creates a problem of endogeneity. The use of laboratory techniques clearly avoids this problem".

${ }^{2}$ Also Peeters and Vorsatz (2013) focus their attention on immaterial sanctions and rewards in the form of emoticons. In their design however every subject may transmit only a single type of emoticon per treatment (a frowny in one condition, a smiley in the other) to each group member (being then informed about the number of received emoticons). We instead allow each subject to send a positive or a negative feedback to only one member of the group. More details will be provided in the next section.

${ }^{3}$ There is already some experimental evidence about the effects of material punishment among different samples of subjects. Bigoni et al. (2013) compare students and clerical workers in a repeated prisoners' dilemma with and without material punishment. Similarly, Dickinson et al. (2015) compare students and police commissioners in a VCM with material sanctions and rewards.

${ }^{4}$ The two companies operate in similar sectors: more details in Dragone et al. (2015). While the participants supplied
} 
subjects were inexperienced and participated in only one session. At the beginning of each session, participants were seated at random in front of computer workstations which were isolated with panels. The experiment was fully computerized using z-Tree (Fischbacher, 2007), and was divided into two parts. In the first part, we classified subjects based on their other-regarding preferences measured by means of three alternative methods which are widely used in the experimental literature: a one-shot Dictator Game, a one-shot Public Good Game with strategy method, and a Decomposed Prisoner's Dilemma. ${ }^{5}$ Subjects could not send feedback to the other participants during this first part of the experiment.

In the second part, participants played a repeated linear VCM in fixed groups of four (partner matching) for 36 periods. The 36 periods were divided in three blocks of 12 periods each. Subjects received a new set of instructions at the beginning of each block. ${ }^{6}$ In each period, subjects were endowed with 20 tokens which could be allocated between a 'private' and a 'public' account. Payoffs were calculated in each period according to the following function, where $g_{i}$ indicates subject $i$ 's contribution to the public account and 0.5 is the marginal individual benefit of the public good:

$$
\pi_{i}=20-g_{i}+0.5 \sum_{j=1}^{4} g_{j}
$$

Since the payoff is strictly decreasing in the individual contribution, the individual optimal choice is to contribute zero irrespective of others' contributions. Essentially, this is a (repeated) prisoners' dilemma in which, for all players, not contributing to the public good is the Nash equilibrium of the one-shot game.

In the first block (periods 1-12), subjects played a standard VCM with no feedback. In the second block (periods 13-24), subjects played the VCM with feedback: subjects could, after observing the individual contributions of the other group members, provide costless, immaterial feedback: approval or disapproval could be expressed sending a smiley (:) or a frowny (:), respectively. ${ }^{7}$ Subjects could send at most one feedback to one of their peers; but could also refrain from giving

by the first company are temporary workers, the subjects from the second company are permanent workers. In Dragone et al. (2015), we analyzed the behavior of the two samples of workers separately and we found that they have very similar other-regarding preferences and analogous behavior in the VCM. Also, we did not detect differences in the way they use the feedback device. Therefore, in this paper, we pool them together.

${ }^{5}$ The description of these tasks and their results are covered in Dragone et al. (2015). For the purpose of the current paper, it suffices to mention that both workers and students went through the same tasks and that no information about payoffs or future tasks was given to subjects (subjects were only informed about their earnings at the very end of the experiment).

${ }^{6}$ The instructions were provided both on screen and on paper and were read out aloud by the experimenter. A copy of the instructions is reported in the Appendix. After reading the instructions, we checked subjects' understanding using a computerized control questionnaire, providing individual clarifications to subjects who answered incorrectly. To enhance comprehension and familiarity with the procedures, we also asked subjects to enter three forced inputs before starting the stage (see Bigoni and Dragone, 2012).

${ }^{7}$ Subjects were allowed to send only one emoticon (a smiley or a frowny) to only one group member. We designed the feedback mechanism this way in order to make emoticons a scarce resource and increase their information value. Since subjects cannot assign emoticons indiscriminately to everyone they need to carefully evaluate who deserves feedback. 
any feedback. In the third block (periods 25-36), subjects played the VCM but could not send any feedback, as in the first block.

Contributions during the first block provide information about the consistency of our results with the existing literature and a benchmark for the later blocks. The second block is meant to measure whether non-material feedback affects individual behavior, while the third block studies whether behavior observed during the second block persists even when non-monetary feedback is no more available. At the end of every period, each subject was informed about his or her own contribution to the public account, the contributions of the other (anonymous) members, ${ }^{8}$ and his or her personal earnings. In periods 13-24, subjects were also informed about the number of frownies and/or smileys received by each group member.

After the 36 periods of the repeated VCM, subjects played an additional task (a Stug Hunt Game with framed instructions) which we do not consider in this paper. ${ }^{9}$ At the end of the experiment, subjects filled in a demographic questionnaire and were paid in private at their desks. The experimental tokens were converted in euros at the exchange rate of 1 token equal to 1 euro cent. Subjects earned, on average, $€ 20.93$ (including a $€ 2$ show-up fee). Each session lasted on average 2 hours.

\section{Results}

We first analyze the data in aggregate to investigate whether immaterial feedback increases cooperation and whether there are differences between students and workers. We then examine how subjects use the feedback mechanism and its impact on future contributions both at aggregate and individual level.

Figure 1: Evolution of contributions over time (students vs. workers)

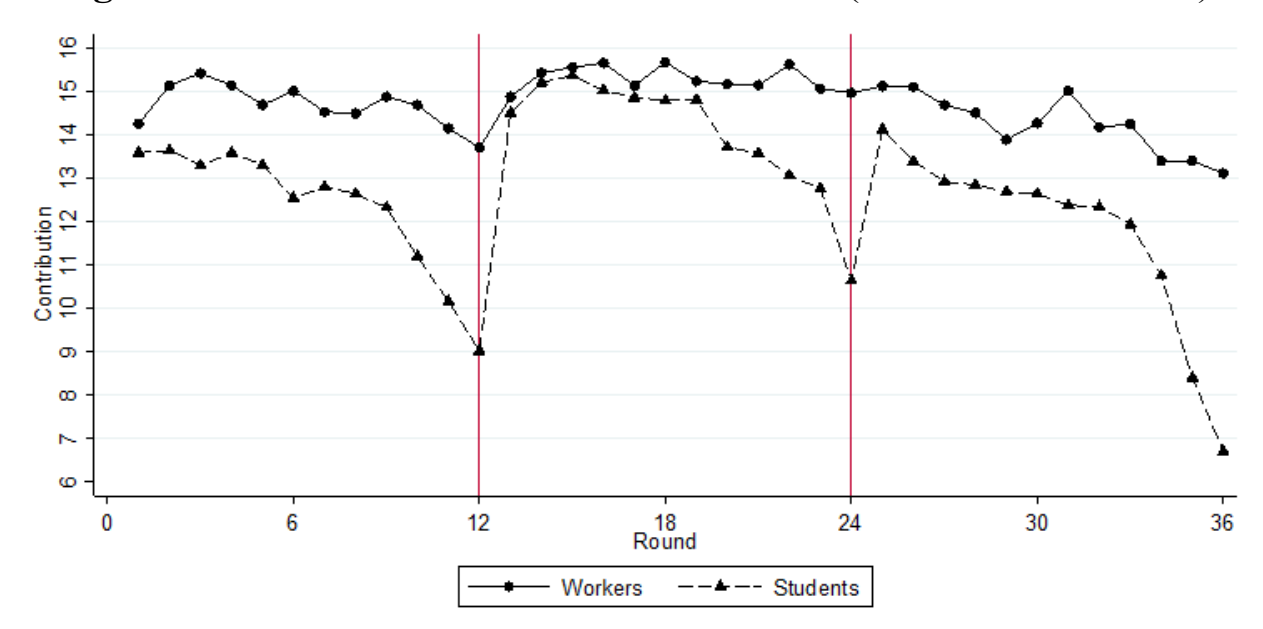

Figure 1 shows the evolution over time of the average contribution of students and workers.

\footnotetext{
${ }^{8}$ The contributions of the other members were displayed in random order by the computer, and a different random ID was assigned to each group member at the beginning of each period.

${ }^{9}$ Subjects were not informed about the content of this future task and so it could not affect behavior in the VCM. We found that students are less cooperative than workers in the framed Stug Hunt Game. More details about this task are available from the authors upon request.
} 
Consistent with previous studies (e.g., Masclet et al., 2003, Noussair and Tucket, 2005, Dugar, 2013, Zylbersztejn, 2015), contributions are higher in periods 13-24 when subjects can send immaterial sanctions or rewards to the other group members. This is true for both students and workers. In particular, the mean contribution of both students and workers in periods 13-24 is significantly larger than their contribution from periods 1-12 and 25-36 (Wilcoxon signed-rank test, $p=0.007$ for students, and 0.001 for workers). ${ }^{10}$ If we compare students to workers, the latter contribute significantly more only when immaterial feedback is not available, that is in periods 112 and 25-36 (Mann-Whitney test, $p=0.051$ ). When subjects can send non-monetary sanctions or rewards (periods 13-24), the average contributions of workers and students are not statistically different $(p=0.318)$ except if we look at the very last three periods, where the contributions of students drop dramatically ( $p=0.064,0.092$, and 0.001 for periods 22,23 , and 24) ${ }^{11}$

Figure 2: Kernel density estimates (students vs. workers)

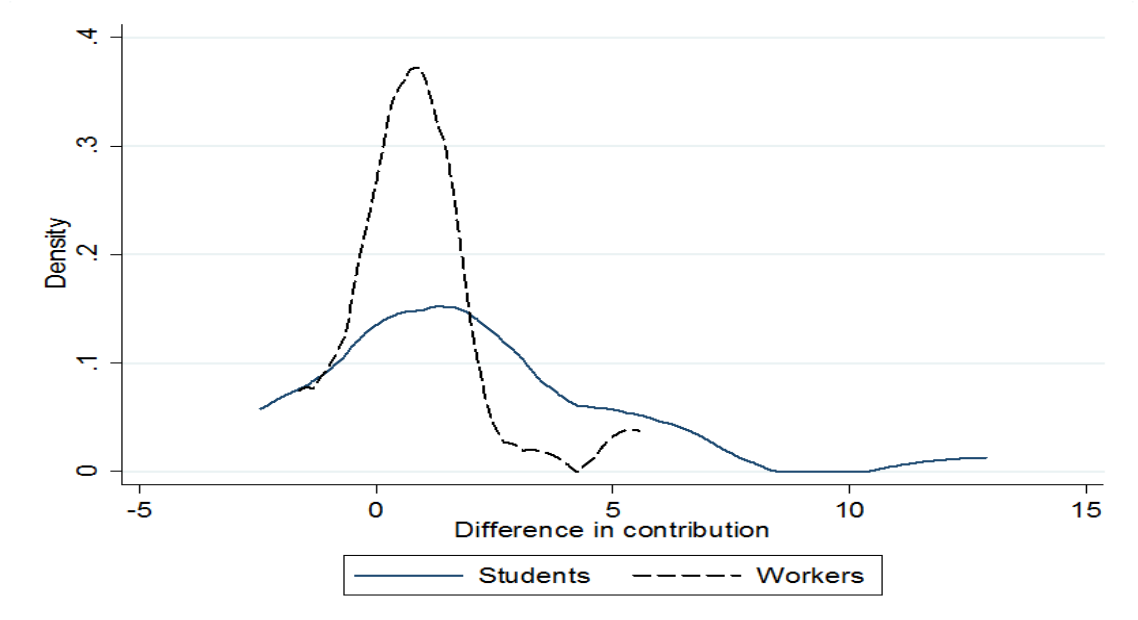

The results presented so far suggest that workers in general free ride less than students, and that both students and workers cooperate more in the presence of immaterial feedback. To investigate the size of the latter effect, we compare the increase in contributions when immaterial feedback is introduced. Students on average increase their contributions by $16.37 \%$, which is almost three times more than the average increase in the workers' contribution (5.77\%). Despite this large difference, a Mann-Whitney $U$ test shows that the increase in contributions of students is only weakly significant larger than the increase in workers $(p=0.091)$. The reason is that there is much more variation in behavior among students than workers. In Figure 2 we plot the kernel density of the differences in contribution with and without immaterial feedback. Most of the groups in the worker sample increase their contribution by around one token when immaterial feedback is introduced

\footnotetext{
${ }^{10}$ Tests are two-tailed throughout the paper. For non-parametric tests, we use the average contribution of each independent group as the unit of observation. For the regression analysis, we use the individual contribution in each period as the unit of observation. Contributions in periods 1-12 are not statistically different from contributions in periods $25-36$ for both students $(p=0.432)$ and workers $(p=0.472)$. We thus pooled the data of the first and third blocks and computed a single average for sessions 1 to 12 and 25 to 36 .

${ }^{11}$ The general decay of contributions over time is more evident in the student sample than in the worker sample. Analogously, during the last three periods, in each block of the VCM the drop in contributions is significantly larger in the student than in the worker treatment $(\mathrm{p}<0.05)$.
} 
(the kernel distribution of workers shows a sharp peak at 0.9). On the contrary, students display much more variation, with one group of students exhibiting an increase in contributions of more than 12 tokens. We can test this finding in two complementary ways. First, a two-sample Kolmogorov-Smirnov test indicates that the two distributions displayed in Figure 2 are significantly different $(p=0.041)$. Second, the variance of the differences in contribution is significantly larger for students compared to workers (two-group variance-comparison test, $p<$ 0.001). Hence we can state the following:

Result 1. Non-monetary feedback induces more cooperation in both students and workers. The magnitude and variance of this effect are larger in the student sample. We can now turn to the analysis of the feedback mechanism and investigate the circumstances under which frownies and smileys are used. We focus on periods 13-24 where immaterial sanctions and rewards are allowed. Figure 3 displays the evolution over time of smileys, frownies, and no message of students and workers, respectively, while Table 1 shows the main summary statistics regarding the use of the feedback device.

Figure 3: Evolution of smileys, frownies and no message over time (students vs. workers)
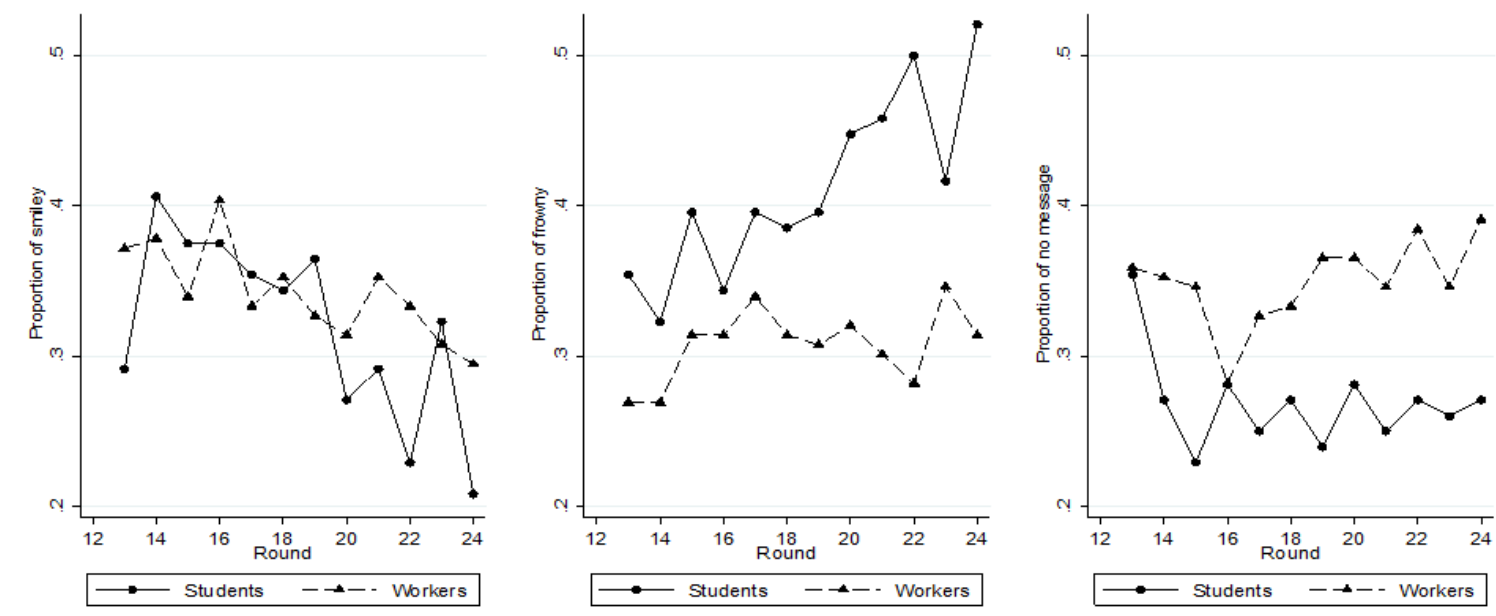

Table 1: Summary statistics for the emoticons

\begin{tabular}{ccccccccc}
\hline \hline & \multicolumn{2}{c}{ Students } & & \multicolumn{2}{c}{ Workers } & & \multicolumn{2}{c}{ All } \\
\cline { 2 - 3 } \cline { 7 - 8 } & Mean & St. dev. & & Mean & St. dev. & & Mean & St. dev. \\
\hline Smiley & 0.32 & 0.47 & & 0.34 & 0.47 & & 0.33 & 0.47 \\
Frowny & 0.41 & 0.49 & & 0.31 & 0.46 & & 0.35 & 0.48 \\
No message & 0.27 & 0.44 & & 0.35 & 0.48 & & 0.32 & 0.47 \\
\hline \multicolumn{2}{l}{ Note: St. dev. = standard deviation. } & & & & &
\end{tabular}

Considering Figure 3, one can see that the number of smileys assigned to group members tends to decrease over time, while the number of frownies tends to increase. The trend of smileys parallels the downward time trend of contributions. Comparing the use that students and workers make of the feedback device, we find that students send significantly more frownies than workers (MannWhitney test, $p=0.019)$ but a similar proportion of smileys $(p=0.650)$. Workers also tend to send less emoticons than students $(p=0.024)$. These differences may be simply explained by the fact 
that students tend to be more free riders than workers, and, therefore, are disapproved more frequently. We will investigate this in more detail later.

Figure 4: Probability of sending a frowny or a smiley depending on the difference between sender's and receiver's contribution (students vs. workers)

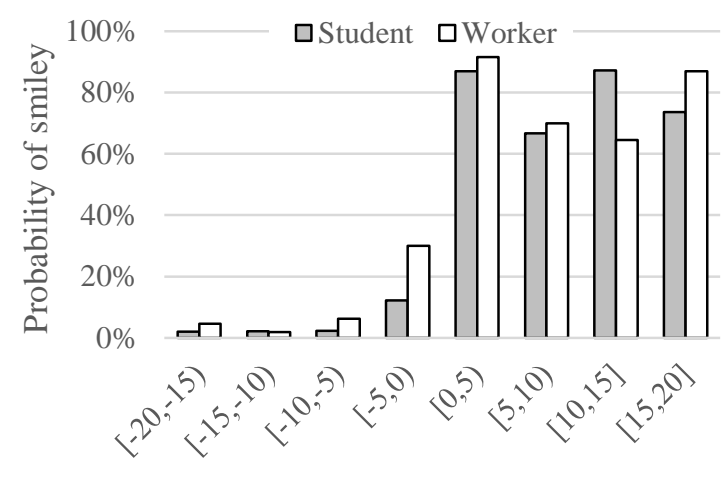

Receiver's minus sender's contribution

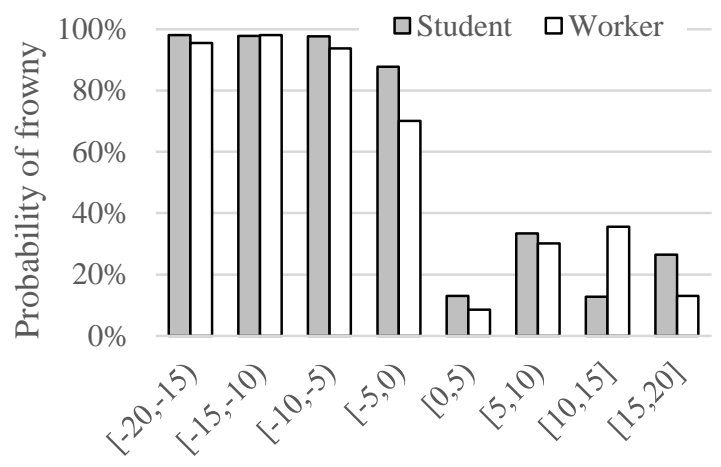

Receiver's minus sender's contribution

To explore the way subjects use the feedback mechanism to approve or disapprove group members, in Figure 4 we show the probability of sending immaterial feedbacks, depending on the difference between the receiver's and the sender's contribution. When the difference is nil, the subject receiving an emoticon has contributed the same amount as the sender; when it is positive the sender has contributed less than the receiver, and when it is negative she has contributed more. Overall, subjects are more likely to send a feedback the more the receiver's contribution deviates from the sender's contribution. The choice of the specific feedback, i.e. whether sending a smiley or a frowny, is related to the sign of the deviation. The distribution of smileys is clearly skewed to the right: they are sent more often to subjects that have contributed more. The distribution of frownies, instead, is skewed to the left: they are sent more often to those who have contributed less. The frequency of sending a frowny is very large (between 80 and 100 percent) when the receiver has contributed at least 5 tokens less than the sender. The frequency of sending a smiley for contributing more than the sender is instead between 60 and 90 percent. Given that subjects can only send one feedback per round, we conjecture that subjects tend to prefer using sanctions, rather than rewards, to stigmatize those who do not conform to the group behavior. These results hold for both students and workers.

In Figure 5 we report the probability of receiving at least one feedback depending on the deviation from the average group contribution. The pattern is qualitatively similar to the one displayed in Figure 4, as smileys are sent more often to subjects that are beneficient to the group (i.e. contribute more than average) and frownies are sent to those who free-ride (i.e. contribute less). ${ }^{12}$

\footnotetext{
${ }^{12}$ Graphical inspection of Figure 5 would suggest students sanction with frownies also those who contribute much more than the group (between 10 and 15 tokens above the average contribution). However, a Mann-Whitney test shows that this result is not significant: for any interval of deviation from the average group contribution represented in Figure 5 , the probability of receiving frownies or smileys is not statistically different $(p>0.1)$ between workers and students.
} 
Figure 5: Probability of receiving at least one frowny or one smiley depending on the deviation from the average group Contribution (students vs. workers)

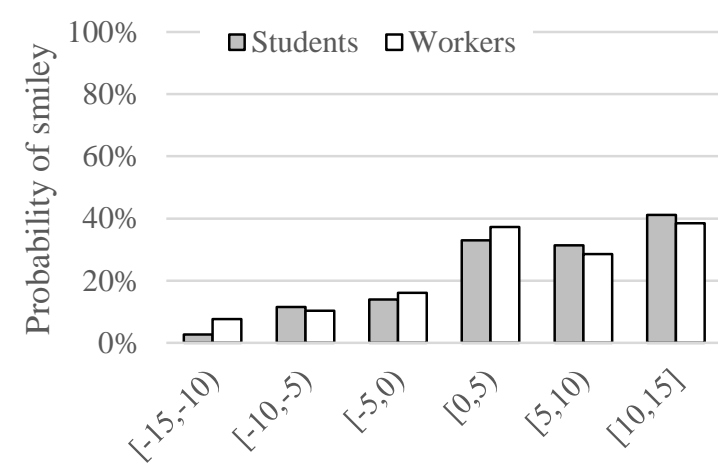

Receiver's minus average group contribution

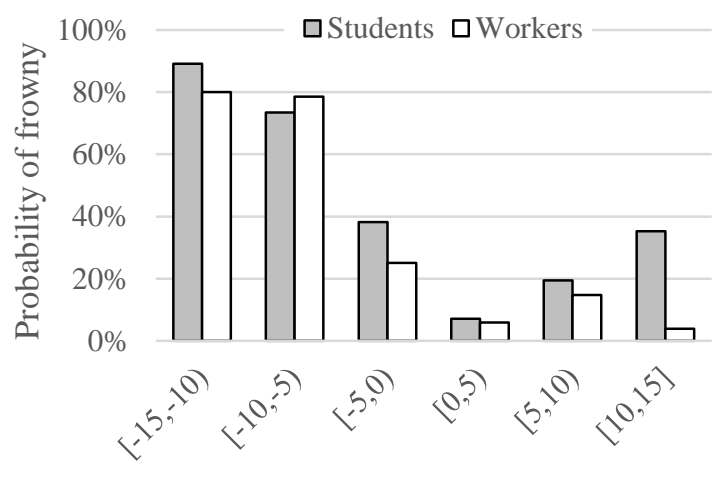

Receiver's minus average group contribution

To provide statistical evidence of the relationship between emoticons and deviation from the average group contribution, we estimate, for each type of emoticon, a mixed effects logistic regression where the dependent variable is a dummy variable that takes the value 1 if a subject receives one or more frownies/smileys in period $t$, and zero otherwise. The independent variables are the average group contribution of group $i$ in $t\left(\bar{C}_{i}^{t}\right)$, the negative and positive deviation of subject $j$ from the average group contribution in $t\left(\left\{\max \left(\bar{C}_{i}^{t}-C_{j, i}^{t}, 0\right)\right\}\right.$ and $\left.\left\{\max \left(C_{j, i}^{t}-\bar{C}_{i}^{t}, 0\right)\right\}\right)$, a dummy for the workers $\left(d_{W}\right)$, and interaction terms between this dummy and all other variables. To control for group and individual effects, we include random effects at group and subject level. Table 2 reports the marginal effects of the two regressions.

Table 2: Mixed effects logistic regressions on the probability of receiving an emoticon

\begin{tabular}{|c|c|c|c|c|c|c|}
\hline & \multicolumn{2}{|c|}{ Smiley } & \multicolumn{2}{|c|}{ Frowny } & \multirow{2}{*}{$\begin{array}{l}\text { Smiley } \\
\text { S. vs. W. }\end{array}$} & \multirow{2}{*}{$\begin{array}{l}\text { Frowny } \\
\text { S. vs. W. }\end{array}$} \\
\hline & $\mathrm{dy} / \mathrm{dx}$ & se & $\mathrm{dy} / \mathrm{dx}$ & se & & \\
\hline \multicolumn{7}{|l|}{ Students } \\
\hline Student $\left(d_{W}=0\right)$ & $0.241 * * *$ & 0.029 & $0.206 * * *$ & 0.018 & 0.642 & $0.052 *$ \\
\hline Average group contribution & $0.014 * * *$ & 0.004 & -0.004 & 0.003 & 0.105 & 0.371 \\
\hline Deviation from average $(+)$ & $0.022 * * *$ & 0.006 & $0.009 * *$ & 0.004 & 0.792 & 0.853 \\
\hline Deviation from average $(-)$ & $-0.015^{* *}$ & 0.007 & $0.051 * * *$ & 0.005 & 0.418 & 0.225 \\
\hline \multicolumn{7}{|l|}{ Workers } \\
\hline Worker $\left(d_{W}=1\right)$ & $0.258 * * *$ & 0.023 & $0.166 * * *$ & 0.011 & & \\
\hline Average group contribution & $0.025 * * *$ & 0.005 & 0 & 0.002 & & \\
\hline Deviation from average $(+)$ & $0.024 * * *$ & 0.006 & $0.010 * * *$ & 0.003 & & \\
\hline Deviation from average $(-)$ & $-0.022 * *$ & 0.006 & $0.044 * * *$ & 0.004 & & \\
\hline $\mathrm{Obs}$ & 3024 & & 3024 & & & \\
\hline Log likelihood & -1605.120 & & -1079.313 & & & \\
\hline Df & 7 & & 7 & & & \\
\hline Prob $>$ F & 0.000 & & 0.000 & & & \\
\hline
\end{tabular}

Notes: The table displays marginal effects. These are calculated assuming that the random effects are zero. In the last two columns (S. vs. W.) we report the p-values of comparisons between the marginal effects of students and workers. $* \mathrm{p}<0.10,{ }^{* *} \mathrm{p}<0.05,{ }^{* * *} \mathrm{p}<0.01$.

The results of these regressions are in line with the previous observations. Both students and workers use immaterial feedback, and students tend to use immaterial sanctions more than workers. 
Consistent with the graphical inspection of Figures 4 and 5, smileys are significantly more likely to be received by those who contributed more in the group, and are significantly less likely to be received by those who contributed less. These results hold for both students and workers. In addition, smileys are sent more frequently when the average group contribution is high. Considering frownies, two main differences emerge with respect to smileys. First, the level of group contribution per se does not significantly affect the probability of receiving a frowny. Second, the likelihood of receiving a frowny increases when there are deviations from the group behavior, and this occurs both in case of positive and negative deviations. The effect is larger in the latter case. All this can be summarized in the following:

Result 2. Students tend to use immaterial sanctions more than workers.

Result 3. Students and workers send immaterial rewards to group members that contribute more than the group average.

Result 4. Students and workers send immaterial sanctions to group members whose contribution deviates from the group average.

The above results suggests that subjects make use of positive and negative feedback to reward desirable behavior and to sanction deviant one. Such use of feedback suggests that immaterial "stick-and-carrots" incentives are adopted in order to enforce social norms for contribution to the public good (see, e.g., Bicchieri, 2005).

There is an asymmetry in the use of positive and negative feedback: smileys are essentially sent to those who are beneficient to the group, but not to those who free-ride; frownies, instead, are sent to those who free-ride, but also to those who are beneficient. Punishing those who deviate from the norm and contribute more than the group is not consistent with a forward-looking payoff maximizing strategy, but it has already been observed in some previous experiments where material punishment was possible. Herrmann et al. (2008), for example, report that some subjects sanction people who over-contribute with respect to the average of the group.

We can now consider the effect of immaterial feedback on behavior. ${ }^{13}$ We run a multilevel mixedeffects linear model where the dependent variable is the difference in contribution of subject $j$ between two consecutive periods. ${ }^{14}$ Independent variables include the negative and positive deviations of subject $j$ from the average group contribution in $\mathrm{t}-1\left(\left\{\max \left(\bar{C}_{i}^{t-1}-C_{j, i}^{t-1}, 0\right)\right\}\right.$ and $\left.\left\{\max \left(C_{j, i}^{t-1}-\bar{C}_{i}^{t-1}, 0\right)\right\}\right)$, dummies for whether subject $\mathrm{j}$ receives frownies $\left(F_{j}^{t-1}\right)$ or smileys $\left(S_{j}^{t-1}\right)$ in period $\mathrm{t}-1$, a dummy for the workers $\left(d_{w}\right)$, and interaction terms between this dummy and all the other variables. We also control for a time variable and a one-period lag variable.

The results, presented in Table 3, indicate that subjects tend to decrease their contribution when they realize that they have contributed above the average. Workers, however, are less reactive and

\footnotetext{
${ }^{13}$ In the Appendix, we plot the change in contribution between two consecutive periods on the number of smileys or frownies received. Sanctions appear to be very effective in inducing more contribution from one period to the next one. Rewards instead seem to trigger, if anything, less cooperative behavior.

${ }^{14}$ We also ran a random-effects Tobit regression on the difference in contribution between two consecutive periods (as in, e.g., Peeters and Vorsatz, 2013). The results are qualitatively similar to those presented in the paper and are reported in the Appendix.
} 
decrease their contribution less than students. Contributing below the average in the previous round, in contrast, induces an increase in contributions, which is not significantly different among students and workers. These results suggest an overall tendency to conform individual choices to past group behavior.

Table 3: Multilevel mixed-effects linear regression on the difference in contribution between two consecutive periods

\begin{tabular}{ccc}
\hline & $\mathrm{b}$ & $\mathrm{se}$ \\
\hline Deviation from average $(+)$ & $-0.727^{* * *}$ & 0.094 \\
Deviation from average $(-)$ & $0.369^{* * *}$ & 0.114 \\
Worker & $-2.380^{*}$ & 1.284 \\
Worker $\times$ Deviation from average $(+)$ & $0.387^{* * *}$ & 0.12 \\
Worker $\times$ Deviation from average $(-)$ & 0.129 & 0.145 \\
Frowny & -0.145 & 0.461 \\
Smiley & -0.549 & 0.583 \\
Smiley $\times$ Deviation from average $(+)$ & 0.047 & 0.13 \\
Smiley $\times$ Deviation from average $(-)$ & -0.105 & 0.162 \\
Frowny $\times$ Deviation from average $(+)$ & $0.483^{* * *}$ & 0.144 \\
Frowny $\times$ Deviation from average $(-)$ & $0.320^{* *}$ & 0.131 \\
Smiley $\times$ Worker & 0.118 & 0.579 \\
Frowny $\times$ Worker & 0.795 & 0.796 \\
Smiley $\times$ Worker $\times$ Deviation from average $(+)$ & -0.199 & 0.172 \\
Smiley $\times$ Worker $\times$ Deviation from average $(-)$ & 0.105 & 0.203 \\
Frowny $\times$ Worker $\times$ Deviation from average $(+)$ & $-0.741^{* * * *}$ & 0.217 \\
Frowny $\times$ Worker $\times$ Deviation from average $(-)$ & $-0.290^{*}$ & 0.17 \\
Lag of deviation in contribution & $-0.223^{* * *}$ & 0.032 \\
Period & $-0.161^{* * *}$ & 0.051 \\
Worker $\times$ Lag of deviation in contribution & -0.039 & 0.042 \\
Worker $\times$ Period & $0.124^{*}$ & 0.064 \\
Constant & $2.867^{* * *}$ & 1.008 \\
\hline Obs & 2520 & \\
Log likelihood & -7404.891 & \\
Df & 21 & \\
Prob $>$ F & 0 & \\
\hline & &
\end{tabular}

Notes: $* \mathrm{p}<0.10,{ }^{* *} \mathrm{p}<0.05,{ }^{* * *} \mathrm{p}<0.01$.

When considering non-monetary feedback, we find that frownies significantly affect how subjects react when their contribution is below or above the average, and this response is different among workers and students. In particular, disapproved students whose previous contribution was above the average decrease less their contribution than non-disapproved ones; if instead the previous contribution was below the average, they increase more their contribution than non-disapproved ones. This result is consistent with the literature, and provides support for the effectiveness of immaterial feedback in promoting social conformism among students.

In contrast, and somehow surprisingly, workers receiving frownies do not contribute more, but rather contribute less when they are disapproved. This result emerges both when they have 
contributed more than average in the previous round (the overall effect is that they decrease more their contribution), and when they have contributed less (they do not increase their contribution).

Interestingly, smileys produce no significant effect on the subjects' contributions, both among students and workers.

Result 5. Non-monetary sanctions help sustaining higher cooperation among students and tend to have a negative effect on workers' contributions.

Finally, we also investigated whether subjects who send a smiley or a frowny contribute more or less in the subsequent period. In particular, we ran the same regression of Table 3, except that now the emoticons dummies capture whether a subject has sent an emoticon, or not. The results are reported in the Appendix, and they show that subjects who had sent a smiley and contributed below the average in the previous period tend to decrease their contribution in the next period.

\section{Discussion and conclusion}

We examine how students and workers react to non-monetary feedback in a VCM setting. Our data show that both students and workers increase their contributions when immaterial sanctions and rewards can be sent to co-players. ${ }^{15}$ The size of the effect is larger for students who start from very low contributions when immaterial feedback is not allowed, and reach similar levels of cooperation as workers when communication is permitted. One possible explanation is that there is a cap, over which subjects are unable to go, on the maximum level of cooperation that subjects can achieve using immaterial feedback. This means that for certain particularly virtuous populations (such as workers, in our case), the introduction of immaterial feedback may have only a very tiny effect on contributions. In such a case, it may be inefficient to set up a system of immaterial feedback (e.g. in a company, this could be done by expanding the opportunities of communication between employees or organizing employee-honoring events/awards such as "the best employee of the month") if the costs of doing so are too high.

We also find that non-monetary sanctions partially counterbalance the tendency of students to lower their contribution when the latter is above the average, and they boost the propensity to increase contributions when they are below the average. This is not the case for workers: immaterial sanctions increase their tendency to lower contributions when the latter are above the average. In other words, immaterial sanctions may have a crowding out effect on the intrinsic motivation of virtuous workers who receive negative feedback. In a company, this may entail substantial economic costs and inefficiencies especially if the cooperative spirit and social cohesion of the workplace rely on these "outperforming" employees.

In line with previous studies (e.g. Masclet et al., 2003; Dugar, 2013; Peeters and Vorsatz, 2013),

\footnotetext{
15 This result is consistent with Masclet et al. (2003), Noussair and Tucket (2005), Dugar (2013), and Zylbersztejn (2015) but not with Peeters and Vorsatz (2013) who did not find a significant increase in the average group contribution (only variance increases in their experiment). As Peeters and Vorsatz (2013) pointed out, a possible explanation of this non-significant result is that, differently from our and other studies, they did not explicitly link the feedback to approvals/disapprovals.
} 
we also find that both students and workers are more likely to assign immaterial sanctions to group members who contribute less than group average, and immaterial rewards to those that contribute more. ${ }^{16}$ This is reassuring for the internal validity of our findings, because it suggests that our subjects did not use the feedback device in a random fashion. ${ }^{17}$

To conclude, we run an artefactual field experiment to compare a standard subject pool of undergraduate students with a pool of workers and check the external validity of experiments that measure the effect of immaterial sanctions and rewards in VCM. Our findings contribute to the general discussion on the robustness of experimental results and their generalizability to real-world interactions. ${ }^{18}$ In addition, they provide interesting insights on how immaterial feedback may affect work organization. The main message we can derive from our study is that caution must be adopted in employing feedback mechanisms in the workplace since, among workers, they may not work as efficiently and effectively as among undergraduate students in typical laboratory experiments.

\section{References}

Bicchieri, C. (2005), "The Grammar of Society: The Nature and Dynamics of Social Norms". Cambridge University Press.

Bigoni, M., G. Camera, and M. Casari (2013), "Strategies of cooperation and punishment among students and clerical workers." Journal of Economic Behavior \& Organization, 94, 172-182.

Bigoni, M., and D. Dragone (2012), "Effective and Efficient Experimental Instructions." Economics Letters, 117, 460-463.

Bradler, C., R. Dur, S. Neckermann, and A. Non (2013), "Employee recognition and performance: A field experiment." ZEW-Centre for European Economic Research Discussion Paper, (13-017).

Derks, D. (2007), "Exploring the Missing Wink: Emoticons in Cyberspace." PhD thesis, Open Universiteit Nederland.

Dickinson, D. L., D. Masclet, and M. C. Villeval (2015), "Norm enforcement in social dilemmas: An experiment with police commissioners." Journal of Public Economics, 126, 74-85.

Dragone, D., F. Galeotti, and R. Orsini (2015), "Students, Temporary Workers and Co-Op Workers: An Experimental Investigation on Social Preferences." Games 6(2), 79-123.

Dugar, S. (2013). "Non-monetary incentives and opportunistic behavior: Evidence from a laboratory public good game." Economic Inquiry, 51(2), 1374-1388.

\footnotetext{
${ }^{16} \mathrm{We}$ also find that, all things being equal, students tend to use immaterial sanctions more than workers. A possible explanation is that workers may better anticipate the potential negative effects of non-monetary sanctions on their colleagues and, therefore, tend to use them with more caution. We did not collect information on friendship relationships among the participants, hence we cannot exclude that some of the participants of each session knew each other or were friends. However, anonymity in the whole experiment has been granted and alleviates this possible confounding factor.

${ }^{17} \mathrm{We}$ also find some evidence of anti-social (immaterial) punishment. This is also consistent with previous studies (see, e.g., Hermann et al., 2008).

${ }^{18}$ For a recent overview, see Fréchette and Schotter (2015).
} 
Fehr, E., and S. Gächter (2000), "Cooperation and punishment in public goods experiments." American Economic Review, 90, 980-994.

Fischbacher, U. (2007), "Z-Tree: Zurich Toolbox for Ready-Made Economic Experiments." Experimental Economics, 10, 171-178.

Fréchette, G. R., and A. Schotter (Eds.) (2015), Handbook of Experimental Economic Methodology. Oxford University Press.

Greiner, B. (2015), "Subject Pool Recruitment Procedures: Organizing Experiments with ORSEE." Journal of the Economic Science Association, 1(1), 114-125.

Harrison, G. W., and J. A. List (2004), "Field experiments." Journal of Economic literature, 42(4), $1009-1055$.

Herrmann, B., C. Thöni, and S. Gächter (2008), “Antisocial punishment across societies.” Science, 319(5868), 1362-1367.

Masclet, D., C. Noussair, S. Tucker, and M.-C. Villeval (2003), "Monetary and non-monetary punishment in the voluntary contributions mechanism." American Economic Review, 93, 366-380.

Noussair, C., and S. Tucker (2005), "Combining monetary and social sanctions to promote cooperation." Economic Inquiry, 43, 649-660.

Peeters, R., and M. Vorsatz (2013), "Immaterial rewards and sanctions in a voluntary contribution experiment." Economic Inquiry, 51(2), 1442-1456.

Sefton, M., R. Shupp, and J. Walker (2007), "The effect of rewards and sanctions in provision of public goods.” Economic Inquiry, 45, 671-690.

Zylbersztejn A. (2015), "Nonverbal feedback, strategic signaling and nonmonetary sanctioning: new experimental evidence from a public goods game". Research in Experimental Economics, 18. 


\section{Appendix}

A.1 Instructions (only VCM) ${ }^{21}$ [Translation from Italian; bold, italics and other formatting options are as in the original version of the instructions; in total there were 7 stages: the first three form the classification part, the following three the repeated VCM (three twelve-period blocks), and the last one the Stag Hunt Game.]

\section{STAGE FOUR}

\section{Situation}

You will make choices similar to those of stage two, the one in which you received a sum of money and had to choose how much to invest in a common project and how much to put in your personal account.

As before, the sum of money invested in the project is doubled and then divided among four anonymous participants, and your earnings will be the sum of these florins and of those that you put in your personal account.

The participants in your group will be randomly selected by the computer from all the participants of this experiment and they will remain the same throughout this stage.

Unlike before, every time you and the other three participants choose how much to invest in the project, the individual contributions will be immediately communicated to all participants in the group. To protect anonymity, the participants are indicated with letters A, B, C or D that the computer randomly assigns at each round. This means, for example, that letter A can indicate different people in the course of the stage.

Along with your choice of contributing in the project, we will ask you what you think the others are contributing to the project, on average. If your prediction is at 3 or less florins from the actual average, you will earn three extra florins.

\section{What you should do in stage four}

This stage consists of 12 rounds. In each round you are given 20 florins and you are asked to choose

\footnotetext{
${ }^{21}$ For earlier parts, see Dragone et al. (2015).
} 
how much to invest in the project (12 choices), and to indicate what you think is the average contribution of the other participants (12 forecasts).

\section{Results}

After you have made your choice and your prediction, you will be informed about the others' contributions and how much you have earned. Payment will take place privately at the end of stage seven.

\section{STAGE FIVE}

\section{Situation}

This stage is similar to the previous stage. The members of the group are the same as in stage four. Also in this stage you will receive 20 florins in each round. In each of the 12 rounds, you are asked to choose how much to invest in the project (12 choices) and to indicate what you think is the average contribution of the other participants (12 forecasts).

However, unlike in the previous stage, after seeing the contributions of the other participants and your earnings, you can choose whether to send a message to one of the other participants.

You can choose between three symbols: $(;),-;$, or $\odot$. The first symbol means: "I approve what you did", the second "I disapprove what you did", and the third one "I have nothing to say".

If, for example, you are participant A, you will see this screen:

\begin{tabular}{|c|c|c|c|}
\hline & (:) & : & ; \\
\hline Partecipante B & $\checkmark$ approvo quello che hai fatto & disapprovo quello che hai fatto & \\
\hline Partecipante C & $\mathrm{c}$ approvo quello che hai fatto & $\checkmark$ disapprovo quello che hai fatto & \\
\hline Partecipante D & $\mathrm{C}$ approvo quello che hai fatto & $c$ disapprovo quello che hai fatto & \\
\hline & & & $\checkmark$ non ho niente da dire \\
\hline
\end{tabular}

Each group member can send only one message, if he or she wishes, but may receive more than one. So a person can receive up to three messages if the other participants have sent their message to the same person.

Everyone can see the messages received by the others, but to protect the anonymity you will not know the identity of the person who sent the message. 
Before starting we will do some tests on the use of messages.

[Here we asked subjects to enter three forced inputs to practice the feedback device]

\section{What you should do in stage five}

In this stage we ask you to choose how much to invest in the project and to indicate what you think is the average contribution of the other participants.

After all members of the group have made their choice, you will be informed about the others' contributions and how much you have earned. Then you can send a message to another member of the group, if you wish.

This procedure is repeated for 12 times. Remember that the letters that identify the members are assigned randomly by computer and that the same letter does not always indicate the same person. In other words, you could be initially called as the person B, then as the person A, then as the person D etc.

\section{STAGE SIX}

\section{Situation}

This stage is similar to the previous stage. The members of the group are the same as in stages four and five.

Also in this stage you will receive 20 florins in each round, and there will be 12 rounds. In each round, you are asked to choose how much to invest in the project and to indicate what you think is the average contribution of the other participants.

However, you cannot now anymore send messages to other participants. In other words, this stage is equal to stage four and you have to choose 12 times how much to invest in the project and indicate 12 times what you think is the average contribution of the other participants.

\section{Results}

You will immediately know how much you earn after each round, and you will receive the payment privately at the end of stage seven. 


\section{A.2 Effect of receiving an emoticon on the difference in contribution between two consecutive periods}

Random-effects Tobit regression on the difference in contribution between two consecutive periods

\begin{tabular}{|c|c|c|}
\hline & $\mathrm{b}$ & se \\
\hline Deviation from average $(+)$ & $-0.749 * * *$ & 0.105 \\
\hline Deviation from average $(-)$ & $0.376^{* * *}$ & 0.127 \\
\hline Worker & $-2.361 *$ & 1.313 \\
\hline Worker $\times$ Deviation from average $(+)$ & $0.407 * * *$ & 0.124 \\
\hline Worker $\times$ Deviation from average $(-)$ & 0.139 & 0.149 \\
\hline Frowny & -0.148 & 0.473 \\
\hline Smiley & -0.588 & 0.599 \\
\hline Smiley $\times$ Deviation from average $(+)$ & 0.043 & 0.135 \\
\hline Smiley $\times$ Deviation from average $(-)$ & -0.119 & 0.166 \\
\hline Frowny $\times$ Deviation from average $(+)$ & $0.507 * * *$ & 0.148 \\
\hline Frowny $\times$ Deviation from average $(-)$ & $0.340 * *$ & 0.135 \\
\hline Smiley $\times$ Worker & 0.136 & 0.593 \\
\hline Frowny $\times$ Worker & 0.766 & 0.814 \\
\hline Smiley $\times$ Worker $\times$ Deviation from average $(+)$ & -0.205 & 0.178 \\
\hline Smiley $\times$ Worker $\times$ Deviation from average $(-)$ & 0.11 & 0.207 \\
\hline Frowny $\times$ Worker $\times$ Deviation from average $(+)$ & $-0.754 * * *$ & 0.223 \\
\hline Frowny $\times$ Worker $\times$ Deviation from average $(-)$ & $-0.294^{*}$ & 0.174 \\
\hline Lag of deviation in contribution & $-0.226 * * *$ & 0.037 \\
\hline Period & $-0.162 * * *$ & 0.052 \\
\hline Worker $\times$ Lag of deviation in contribution & -0.041 & 0.043 \\
\hline Worker $\times$ Period & $0.122 *$ & 0.066 \\
\hline Constant & $2.890 * * *$ & 1.031 \\
\hline Obs & 2520 & \\
\hline Log likelihood & -7383.703 & \\
\hline Df & 21 & \\
\hline Prob $>$ F & 0 & \\
\hline
\end{tabular}




\section{A.3 Effect of sending an emoticon on the difference in contribution between two consecutive periods}

Random-effects Tobit regression on the difference in contribution between two consecutive periods

\begin{tabular}{|c|c|c|}
\hline & $\mathrm{b}$ & se \\
\hline Deviation from average $(+)$ & $-0.359 * *$ & 0.179 \\
\hline Deviation from average $(-)$ & $0.669 * * *$ & 0.102 \\
\hline Worker & $-2.819 * *$ & 1.363 \\
\hline Worker $\times$ Deviation from average $(+)$ & -0.18 & 0.206 \\
\hline Worker $\times$ Deviation from average $(-)$ & -0.053 & 0.118 \\
\hline Frowny & 0.327 & 0.534 \\
\hline Smiley & -0.256 & 0.557 \\
\hline Smiley $\times$ Deviation from average $(+)$ & -0.132 & 0.24 \\
\hline Smiley $\times$ Deviation from average $(-)$ & $-0.232 *$ & 0.123 \\
\hline Frowny $\times$ Deviation from average $(+)$ & -0.213 & 0.189 \\
\hline Frowny $\times$ Deviation from average $(-)$ & 0.17 & 0.143 \\
\hline Smiley $\times$ Worker & 0.128 & 0.666 \\
\hline Frowny $\times$ Worker & 1.012 & 0.72 \\
\hline Smiley $\times$ Worker $\times$ Deviation from average $(+)$ & 0.302 & 0.289 \\
\hline Smiley $\times$ Worker $\times$ Deviation from average $(-)$ & 0.161 & 0.155 \\
\hline Frowny $\times$ Worker $\times$ Deviation from average $(+)$ & 0.276 & 0.234 \\
\hline Frowny $\times$ Worker $\times$ Deviation from average $(-)$ & -0.279 & 0.187 \\
\hline Lag of deviation in contribution & $-0.234 * * *$ & 0.036 \\
\hline Period & $-0.184 * * *$ & 0.052 \\
\hline Worker $\times$ Lag of deviation in contribution & -0.032 & 0.043 \\
\hline Worker $\times$ Period & $0.148 * *$ & 0.066 \\
\hline Constant & $2.949 * * *$ & 1.079 \\
\hline Obs & 2520 & \\
\hline Log likelihood & -7407.184 & \\
\hline Df & 21 & \\
\hline Prob $>$ F & 0 & \\
\hline
\end{tabular}

Notes: Random effects are at individual level. ${ }^{*} \mathrm{p}<0.10,{ }^{* *} \mathrm{p}<0.05,{ }^{* *} \mathrm{p}<0.01$. 


\section{A.4 Effect of receiving an emoticon on the difference in contribution between two consecutive periods}

Effect of receiving a smiley or a frowny on the change in contribution between two consecutive periods (students vs. workers)

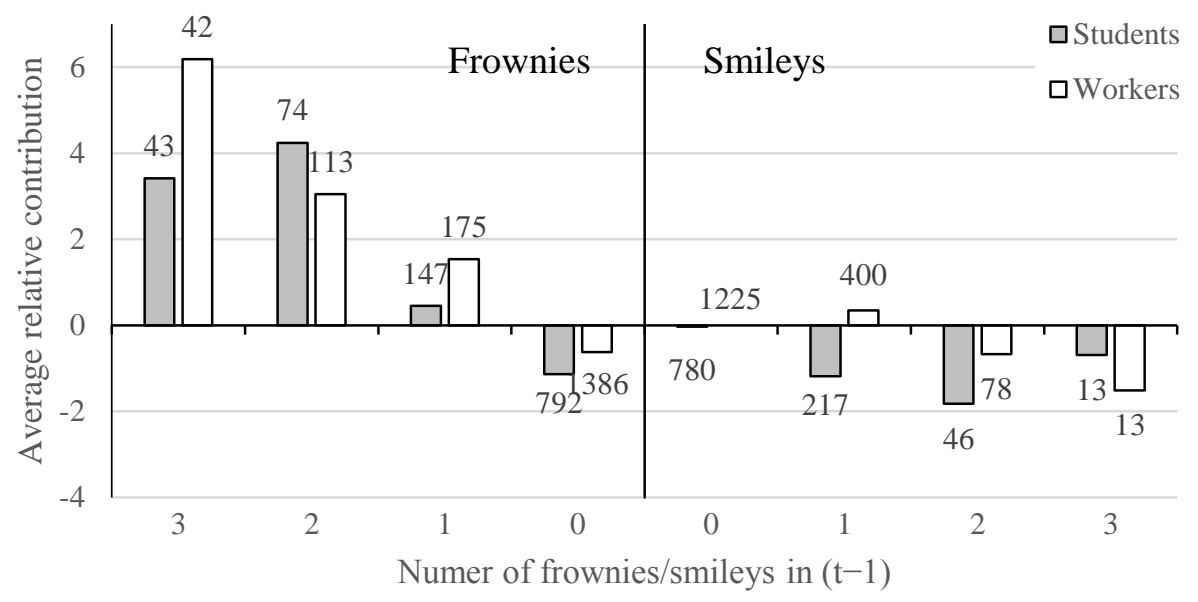

Notes: The figure shows the relationship between the number of frownies/smileys received by a subject and his or her change in contribution between the next and current period. The y-axis indicates the number of frownies/smileys, from 0 to 3 inclusive, that a subject could receive in given period $t$. The $x$-axis measures the average relative contribution of the subject between periods $t$ and $t+1$. The number of observations are reported on top or below each bar. 